\title{
Development of a Child with Joubert Syndrome
}

\author{
M. Carmen Torres, M. José Buceta, and M. Consuelo Cajide \\ University of Santiago de Compostela
}

The article describes the development of a child with Joubert Syndrome who, since the age of 16 months, has received personalized stimulation therapy at home and in the Early Intervention Unit (EIU) of the Faculty, in each of the five areas considered by the Portage Guide to Early Education: socialization, language, self-help, cognition, and motoricity. Repeated evaluations during the treatment (up to age 40 months) showed slow progress in all developmental areas, as well as in general attitude to and capacity for learning. During treatment, greatest progress was made in the areas of cognition and communication. Key worls: Joubert syndrome, vermis agenesia, ealy intervention

Este artículo describe el desarrollo de un niño con síndrome de Joubert, atendido en la Unidad de Atención Temprana de una Facultad de Psicología. El sujeto se incorporó a la edad de 16 meses a un programa individualizado de estimulación temprana en cada una de las cinco áreas consideradas por la Guia Portage de Atención Temprana: socialización, lenguaje, auto-ayuda, cognición y motricidad. El programa se puso en práctica tanto en la unidad como en el hogar. Las evaluaciones realizadas a lo largo del periodo de tratamiento (hasta la edad de 40 meses) mostraron una evolución positiva, aunque muy lenta, en todas las áreas de desarrolio, en la actitud general y en la capacidad de aprendizaje. Durante ef tratamiento, los mayores progresos se realizaron en el área cognitiva y en el área de comunicación.

Palabras clave: sindrome de Joubert, agenesia de vermis, atención temprana

Correspondence concerning this article should be addressed to: $\mathrm{M}^{\mathrm{a}}$ Carmen Torres, Unjversidad de Santiago. Departamerto de Psicología Evolutiva y de la Educación. 15706 Santiago de Compostela (Spain). Fax: 981-521581. E.mail: ctorres@usc.es 
The Joubert syndrome is a rare autosomal recessive disorder first described by Joubert, Eisenting, Preston, and Andermann in 1969. To date, about 200 cases have been reported in the world literature (Maria, Bolthauser, Palmer, \& Tran. 1999). Its neurological determinant is hypoplasia or absence of the vermis. According to Steilin (1998), its invariant clinical characteristics are a "lish mouth," syndactyly or polydactyly, hypotonia, ataxia, and frequent rhythmic protusion of the tongue. Additionally, during the neonatal period, many cases show abnormal respiration (apnea or tachypnea), and many show eye abnormalities, such as nystagmus, strabismus, or congenital retinal dystrophy (Pellegtino, Lenssch, Muenke, \& Chance, 1997). Some patients develop self-injurious behavior, such as selfmutilation, head banging, and self-biting (Holroyd, Reiss, \& Bryan, 1991). Saraiva and Baratser (1992) proposed the fulfilment of four conditions as a diagnostic criterion: absence or hypoplasia of the vermis, hypotonia, developmental retardation, and the presence of any of the other signs noted above. Maria et al. (1999) drew up the revised list of diagnostic criteria shown in Table 1 , in view of the marked phenotypic variability that hampers differential diagnosis with respect to Dandy-Walker deformity, cerebellar vermian hypoplasia, oligophrenia, congenital ataxia, hepatic fibrosis, Aruma syndrome, or Leber's congenital amaurosis (Houdon, Ohno, Takashimas, \& Takeshita, 1986; Bolthauser, 1991; Saraiva \& Baraitser, 1992; Maria, Hoang, \& Tusa. 1997).
The molecular basis of the Joubert syndrome and the chromosomal Jocation of the defective gene are still unknown (Pellegrino et al., 1997). Some authors consider the syndrome to be genetically and clinically heterogeneous, and that its cause may be an alteration of the long arm of chromosome 9 (Saar et al., 1999).

Similarly to Joubert syndrome patients, some autistic children have a hypoplastic vermis (Courchesne, YeungCourchesne, \& Press, 1988). At the same time, some Joubert syndrome patients have autistic characteristics, including stereotyped hand movements (Holroyd et al., 199 J). However, diagnosis of autism in Joubert syndrome patients is hampered by the physiological limitations proper to the syndrome itself (O7onoff, Williams, Gale, \& Miller, 1999): motor deficiencies jimit voluntary movement of the eyes, speech control, respiration and facial expression, all of which are involved in emotional, communicative and social activity and are relevant to diagnosis of autism (Dconna \& Zigler, 1993). As with autistic children, Joubert syndrome patients may fail to make eye-contact or signs, or to exhibit imitation or play behaviour (Ozonoff et al., 1999), but the causes of these delicits may be different. Joubert syndrome does not exclude the possibility of autism, but the prevalence of autism among Joubert syndrome patients is not currently known.

Until quite recently, the vermis was generally considered to be a control center chicfly concerned with motor coordination. Currently, there is evidence that it also plays

Table 1

Revised Diagnostic Criteria

\section{COMMON ABNORMALIJ]ES}

Muscle tone: Hypotonial may be marked in the neonatal period and in infancy.

Balance: $75 \%$ of children learn to sit, approximately at 19 months; $50 \%$ learn to walk, approximately at 4 years. but with extreme calcaneal eversion and unstable gait. Tandem walking is poor.

Development: Development is delayed in a variety of domains, including adaptive behaviors and motor, language, and general development. Children ase pleasant, fricndly, easy to guide and socially well integrated. Developmental delay is often severe.

Neuro-radiology: Magnetic Resonance Imaging (MRI) shows a molar signt it axial plane: 1) deeper-than-trormal posterior interpeduncular fossa, 2) prominent or thickened superior cerebellar peduncles, and 3) vermian hypoplasia or dysplasia. MRI in coronal and axial planes shows clefting of the vermis. MRI in sagittal plane shows abnomally shaped and rostrally displaced $4^{\text {th }}$ ventricle.

Pathology: Vermian hypoplasia or dysplasia. elongation of the caudal midbrain tegmestum, and marked dysplasia of the catual medulla.

\section{ASSOCIATED ABRORMAIJTIES}

Face: High rounded eyebrows, broad nasal bridge and milo epicanthus, anteverted nostrils, triangular-shaped open mouth with irregular tongue protrusion, low-set coarse ears.

Breathing: Episodic hyperpnea and/or apnea in $50 \% 1075 \%$ of patients, most pronounced in the neonatal period and infancy.

Eyes: Retinal dysplasia, colobomas, nystagmus, strabismus, and ptosis. Retinal blindness is rare.

Oculomotor system: Apraxia and vestibulo-ocular cancellation/pursuit defects.

Kidneys: Microsystic renal disease can be progressive.

\section{UNCOMMON AISNORMALITIES}

Polydactyly. macrocephaly, microcephaly, esophageal reflux, soft tissue tongue tumors, epilepsy, congenital heart defects, duodenal atresia, choanal atresia, ocuhr fibrosis, liver anomalies, pectus excavatum, Hirschprung's disease, vocal cord paralysis, occipital meningocele. 
an important cognitive role (Allen, Buxton, Wong, \& Courchesne, 1997). All children with Joubert syndrome exhibit deficient performance of tasks involving motor skills or coordination of the motor and visual systems, and most have cognitive deficits, deficient verbal fluidity, attentional problems and poor social skills (Maria et al., 1997; Fennell. Gitten, Dede, \& Maria, 1999), as well as difficulty in understanding languige (Leuscher, Dede, Gitten, Fennel, \& Maria, 1999). Although there is considerable variability in both motor and cognitive developmen, with Developmental Quotient (DQ) scores ranging from below 30 to 85 (Steilin. Schmid, Landau, Bollschauser, 1997), Joubert syndrome is generally considered to be a severe mental disability (Shoumitro, 1998) with poor prognosis.

Steinlin et al. (1997) report three situations: 1) subjects dying before age 30 months: 2) subjects who are totally dependent on carers due to severe developmental problems, with at least $63 \%$ retardation with respect to the norm for the appropriate age group (Leuscher et al., 1999); and 3) subjects with moderate developmental problems allowing them to work in protected environments. According to Gitten, Dede and Fennell (1998), some 94\% of patients belong to class 2.

Most research on Joubert syndrome has focused on its ncurology. There have been practically no systematic, comprehensive evaluations of the developmental profile of these patients, and very little has been published on their developmental progress. Acknowledging this, Fennell ct al. (1999) have called for longiludinal studies.

In this paper. we describe the development, up to the age of 40 months, of a boy with Joubert syndrome who, since the age of 16 months, has received personalized stimulation therapy at home and in the Early Intervention Unit (EIU) of the Faculty of Psychology at the University of Santiago de Compostela (Spain). The efficacy of stimulation therapy in promoting the development of children with other disabilities has been reported and supported in papers by Buceta and Torres (1995), Torres and Buceta (1996, 1997, 1998), and Torres, Buceta, and Lorenzo (2000), in which the importance of maximum involvement of the patient's family is stressed.

\section{Method}

\section{Participant}

The participant was a male, the second child of young parents. His parent's families show no relevant antecedents. but his sister, 2 years older, is alutistic and attends a special center for autistic children. Aftor an uneventful suporvised gestation. the child was born at term ( 40 weeks), weighing $3,700 \mathrm{~g}$ and measuring $50.5 \mathrm{~cm}$, with Apgar ratings of 7-1010. His cranial circumference was $34.5 \mathrm{~cm}$. He was bottle- fed from bitth with no problems; he was a light slecper.
At age 7 months, his parents began to observe poor muscle tone and control, and at age 10 months, he was admitted to hospital for tests. His gencral condition was good, but he was irritable and his erying was abnormal. He wals facially dysmorphic, with fish mouth, microretrognathia, a nose with a broad base ind prominent bridge, low-inserted ears, and an antimongoloid palpebral fissure. He had a short neck, exhibited mild torsal hypotonia, was unable to control his head when prone, and when seated, kept his had upright but was unstahle and kept his legs splayed. Nystagmus was evident, and visual deficit was suspected, although the fundus was normal. Kidney function analyses, haemogram and clectrocncephalogram (EEG) were also normal. Auditoryevoked potentials showed normal hearing by the right ear and moderate hypoacusis $(15-20 \mathrm{~dB})$ of the left. CT scans showed total agenesis of the cerebellar vermis, contact between the cercbellar hemisphere, and IV ventricle deformity typieal of Joubert syndrome. DQ was estimated as 50 , and developmental age (DA) as 5 months. Joubert syndrome was diagnosed.

At age 16 months, the child was referred to the EIU of the University of Sintiago de Compostela. At thit time, he was extrentely irritated by any approach by an adult other than his mother, and had a passive attitude to surrounding objects, showing no attempt to touch or pick them up. He netther played spontaneously nor imitated persons attempling to play with him. Vocal communication was limited to laughter and crying; neither recognizable spcech nor babbling had developed. He was very disturbed by unfamiliar sounds, but was soothed by his mother's voice and responded appropriately to both her tone of voice and her facial expression. Both coarse and fine motor control were very poor for his age: He had greal difficulty in turning over, whether face up or face down, and in both postures was very irritable. He neither erawled nor wriggled forward, and when puslied, he failed to use his arms to soften the fall, and the severe hypotonia of his lower limbs prevented standing without support. His arms were also hypotonic, especially the left, which severely hampered manipulation.

\section{lnstruments}

The Battelle Developmental Inventory (Newborg, Stock, Wnek, Guidubaldi, \& Svinicki, 1984) comprises a total of 34 items, grouped into the areas corresponding to personal and social, adaptive, motor, communication, and cognitive skills. Scores are expressed as centiles, - scores and equivalent age in months ( $\mathrm{EA}$ ); in this paper we report equivatent ages and a scores.

The Brunet-Lézine Seale for Measuring Psychomotor Development in Early Infancy (Brunet \& Lézine 1965) quantifies development in four areas (posture control and motoricity, hand-cye coordination and relationship to objects, language, and sociability) as both a developmentit quotient score and a developmental age (DA). 


\section{Procedure}

Since the age of 16 months, the participant has had physiotherapy sessions and has received personalized stimulation therapy designed in the EIU by adapting the goals and activities of the Portuge Guide to Early Education (Bluma, Shearer, Frohman, \& Hilliard, 1972), in view of the characteristics and deficits revealed by the appropriate tests (see Instruments) in each of the five areas considered by the Guide: socialization, language, self-help, cognition, and motoricity. The stimulation program was applied in the EIU in four 45-minute sessions each week, and a copy of the protocol was given to the parents, who were individually instructed on its application at home and on auxiliary matcrial that they could use. We emphasized both the child's need for daily stimulation and the desirability of a flexible approach, taking advantage of everyday interactions for application of the protocol. When the goals set in the protocol designed upon admission to the ElU had been achieved, a second multistage protocol was designed and applied, also taking into account the evaluation results. Throughout this period, the work of the psychologists, educators, and physiotherapists of the EIU was supported by pediatricians, social workers, and a rehabilitation specialist who monitored the child's physical development and social and lamily relationships.
Table 2

Brunet-Lézine Scale Developmental Age (DA: in Montls and Days) and Developmental Quotient (DQ) at Chronological Age of 16 Months

\begin{tabular}{lll}
\hline & $\mathrm{DA}$ & $\mathrm{DQ}$ \\
\hline $\mathrm{P}$ & $5 \mathrm{~m}$ & 30 \\
$\mathrm{C}$ & $4 \mathrm{~m} 20 \mathrm{~d}$ & 28 \\
$\mathrm{~L}$ & $3 \mathrm{~m}$ & 16 \\
$\mathrm{~S}$ & $4 \mathrm{~m} 20 \mathrm{~d}$ & 28 \\
Total & $4 \mathrm{~m} 21 \mathrm{~d}$ & 28 \\
\hline
\end{tabular}

Note. $\mathrm{P}=$ Posture control and motoricity; $\mathrm{C}=$ Hand-eye coordination and relationship to objects; $L=$ Language; $S=$ Sociability.

Upon admission to the EIU, the child had an overall mental age of 4 months as measured by the Battelle Developmental Inventory. In view of this, he was then evaluated using the Brunct-Lézinc Scale for Measuring Psychomotor Development in Early Infancy (Brunet \& Lézine, 1965), which is considered more discriminating for low developmental ages. The BrunetLézine results (Table 2) were used as a point of reference in designing the first therapeutic protocol. Subsequent evaluations at the chronological ages of 21,26, 32 and 40 months were carried out using the Battelle Inventory.

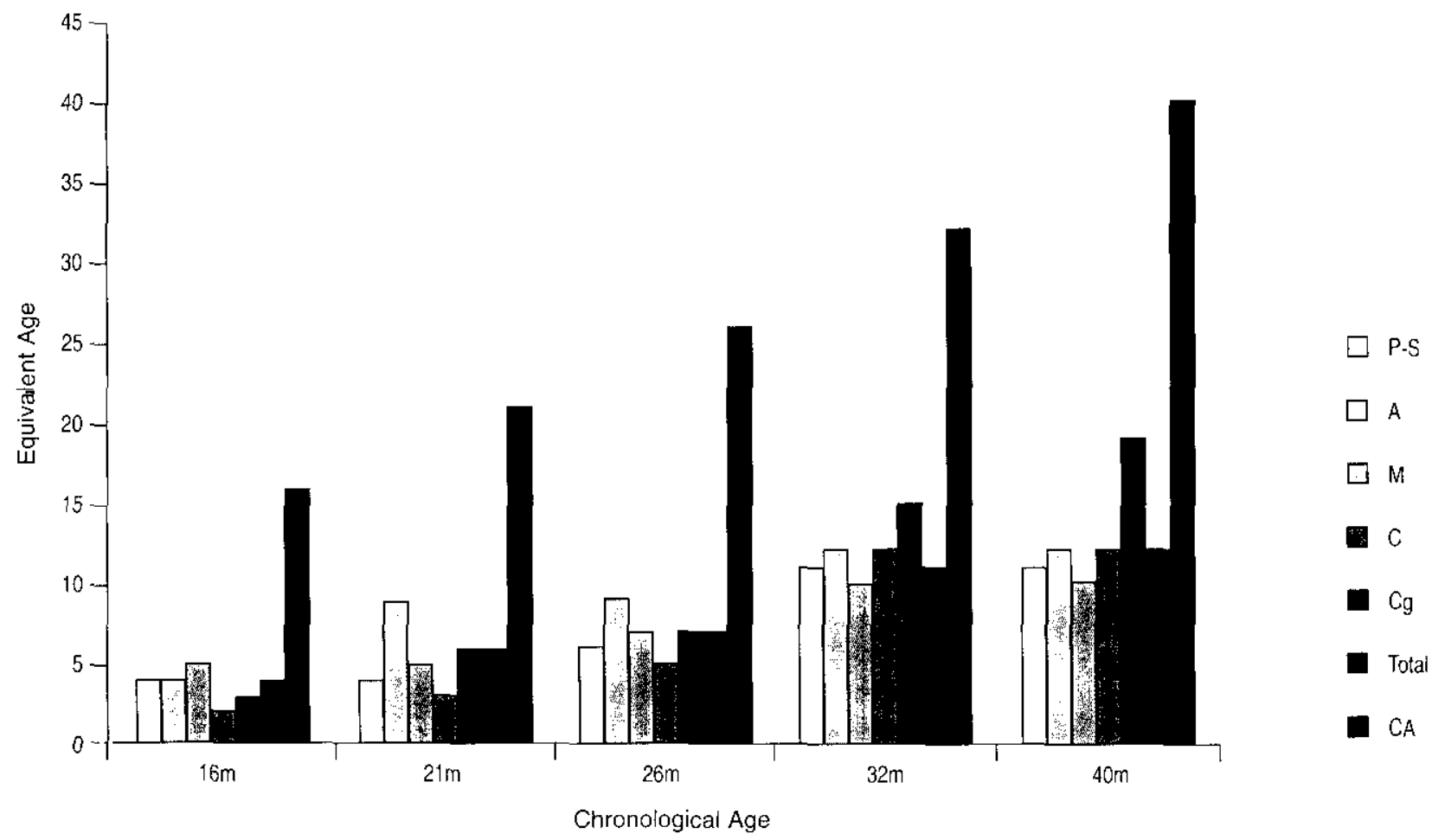

Figure $I$. Battelle Developmental Inventory equivalent ages (EA) at chronological ages $16,21,26,32$, and 40 months. P-S = Personalsocial: $\mathrm{A}=$ Adaptive; $\mathrm{M}=$ Motor; $\mathrm{C}=$ Communication; $\mathrm{Cg}=$ Cognitive: Total = Total Inventory Score: $\mathrm{CA}=$ Chronological $\mathrm{Age}$. 


\section{Results}

From the start of treatment to age 40 months, the participant showed slow but significant progress. Figure 1 compures the Battelle EAs attained in each developmental area in each of the live evaluations carried out. Before treament, overall EA was 4 months, far below the chronological age, 16 months. Although this severe retardation affected all areas, it was slightly more pronounced in the cognitive area and the expressive communication subarea (sce Table 3). During the course of treatment, greatest progress was made in the areas of communication, with successive EAs of $3,5,12$ and 12 montlss, and cognition $(6,7,15$ and 19-2) months). At age 40 months, the lowest EA, 10 months, was for the motor area.

Analysis of the - scores listed in Table 3 shows some differences among the patterns exhibited in the various developmental areas. In the personal/social area, the overall z. score remained fairly stable during the first three evaluations

Table 3

Battelle Developmental hventory z Scores and Equivalent Ages (EA) at Chronological Ages 21, 26, 32, and 40 Months

\begin{tabular}{|c|c|c|c|c|c|c|c|c|c|}
\hline \multirow{2}{*}{ Arcas } & \multicolumn{9}{|c|}{ Chronological Age (months) } \\
\hline & $16^{*}$ & & 21 & & 26 & & 32 & & 40 \\
\hline & & $z$ & EA & $z$ & EA & $z$ & EA & $z$ & EA \\
\hline \multicolumn{10}{|l|}{ PERSONAL-SOCIAL } \\
\hline Interaction with adults & & -3.68 & & -4.35 & & -2.51 & & -5.40 & \\
\hline Expression of fe elings/affect & & -3.22 & & -4.58 & & -3.90 & & -4.85 & \\
\hline Self-concept & & -1.55 & & -2.81 & & -2.45 & & -6.59 & \\
\hline Interaction with peers & & -3.75 & & -2.84 & & -2.84 & & -3.65 & \\
\hline Coping & & -1.35 & & -1.77 & & -1.77 & & -1.96 & \\
\hline Social Role - & & -1.56 & & -1.56 & & -2.16 & & & \\
\hline \multicolumn{10}{|l|}{ ADAPTIVE } \\
\hline Attention & & -3.22 & & -3.92 & & -2.61 & & -4.34 & \\
\hline Eating & & -6.92 & & -4.61 & & -3.50 & & -9.19 & \\
\hline Dressing & & -2.06 & & -2.73 & & -2.20 & & -4.95 & \\
\hline Personal responsibility & & -2.35 & & -1.82 & & -1.82 & & -1.70 & \\
\hline Toileting & & - & & -1.53 & & -1.53 & & -6.11 & \\
\hline TOTAL ADAPTIVE & 4 & -5.11 & 9 & -3.28 & 9 & -2.66 & 12 & -5.75 & 12 \\
\hline \multicolumn{10}{|l|}{ MOTOR } \\
\hline Body Coordination & & -4.78 & & -4.75 & & -4.75 & & -3.44 & \\
\hline Locomotion & & -11.1 & & -16.9 & & -13.9 & & -7.81 & \\
\hline Course Motor Total & 4 & -11.9 & 4 & -7.54 & 5 & -6.83 & 7 & -4.21 & 7 \\
\hline Fine Muscle & & -4.64 & & -2.47 & & -2.000 & & -3.36 & \\
\hline Perceptual Motor & & -5.85 & & -3.56 & & -1.24 & & -1.62 & \\
\hline Fine Motor Total & 4 & -3.84 & 4 & -2.62 & 8 & -1.61 & $15-16$ & -2.45 & $15-16$ \\
\hline TOTAL MOTOR & 5 & -6.1 & 5 & -6.5 & 7 & -5.33 & 10 & -3.94 & 10 \\
\hline \multicolumn{10}{|l|}{ COMMUNICATION } \\
\hline Receptive & $4-5$ & -3.21 & 7 & -2.33 & 8 & -1.48 & $17-18$ & -2.18 & $19-20$ \\
\hline Expressive & 0 & -6.07 & 0 & -4.39 & 2 & -3.20 & 9 & -3.64 & 9 \\
\hline TOTAL COMMUNICATION & 2 & -5.91 & 3 & -3.79 & 5 & -2.66 & 12 & -3.22 & 12 \\
\hline \multicolumn{10}{|l|}{ COGNITIVE } \\
\hline Pcrceptual Discrimination & & -3.55 & & -2.85 & & $-2,06$ & & -3.33 & \\
\hline Memory & & -3.83 & & -3.24 & & -2.27 & & -3.61 & \\
\hline Reasoning \& academic skills & & $-3,19$ & & -0.94 & & 0.19 & & -0.81 & \\
\hline Conceptual Development & & -2.08 & & -1.37 & & -1.37 & & -1.45 & \\
\hline TOTAL COGNITIVE & 3 & -5.53 & 6 & -2.79 & 7 & -1.81 & 15 & -2.07 & $19-21$ \\
\hline INVENTORY TOTAL & 4 & -6.54 & 6 & -4.67 & 7 & -3.70 & 11 & -4.51 & 12 \\
\hline
\end{tabular}

Note. ${ }^{*} z$-scores not calculable at this cvaluation. 
$(-3.67,-3.93,-3.33)$, but dropped significantly at the fourth $(-4.40)$. The least variation of the mean compared to the age group was shown in the coping and social role sub-areas; in the former, the $z$ score dropped by just 0.61 , from -1.35 at the first evaluation to -1.96 at the fourth, whereas in the latter (not assessed by the inventory at the first evaluation), it decreased by 0.60 , from -1.56 at the second evaluation to -2.16 at the fourth. The greatest variation was observed in the self-concept $z$ scorc, which dropped from -1.55 at 21 months to -6.59 at 40 months. Marked decreases in the $z$ score were also observed in interaction with adults $(-3.68$, $-4.35,-2.5 \mathrm{l}$, and -5.40 at successive evaluations) and expression of feelings $(-3.22,-4.58,-3.90$, and -4.85$)$. The boy was able to express emotions and show affection for adults, animals, and toys, but showed little sympathy or affection for other children of his age.

As regards adaptation, an increase in the overall $z$ score $(-5.11,-3.28$, and -2.66 at the first three evaluations) was followed by a return to a very low level $(-5.75)$ at the fourth (see Table 3). Personal responsibility showed mild improvement from $-2.3510-1.70$, but a slight improvement in attention was followed by a drop to -4.34 at 40 months. Dressing -which remained more or less stable during the first three evaluations- also decreased abruptly at the fourth $(-4.95)$, and toileting fell from -1.53 in the second and third evaluations (toileting is not scored for children as young as 21 months) to -6.11 in the fourth. Eating, which had improved from -6.92 to -3.50 at the third evaluation, also dropped sharply in the fourth to -9.19 , partly because of inappropriate action by the parents in this area. Despite of these poor quantitative results, the specialists attending the child noted a qualitative improvement in his ability to pay attention to what was asked of him, and to collaborate in simple activities. It should also be pointed out that progress in the adaptive area was clearly hindered by his general hypotonia and associated total lack of autonomy.

In spite of the persistent hypotonia, progress in the motor area was more satisfactory, especially as regards fine motor control, which showed a rise in EA from 4 to $15-16$ months. In particular, an evident improvement in manipulative ability accompanied an increase in perceptual motor $z$ score from -5.85 to -1.62 , although oscillation of the $z$ score for fine muscle control reflccted the instability of acquired competence. In the coarse motor area, EA only increased from 4 to 7 months, but the $z$ score improved for both body coordination (from -4.78 to -3.44 ) and locomotion (from -11.1 to -7.81 ). At 40 months, the child was able to walk with help, but was still very limited as regards crawling and unsupported standing.

As noted above, progress in communication was more marked than in any other area except cognition. As regards expressiveness, the boy's initial total lack of interest in communication was replaced by the ability, at 40 months, to make his needs known by means of gestures and to imitate word sounds (although word sounds utterance was neither spontancous nor associated with surrounding objects or needs). Receptiveness improved even more: At 40 months the child was able to understand and react appropriately to different tones of voice, to associate actions and objects, and to obey instructions and accompany them with gestures, although understanding of certain adverbial forms and possessives remained poor.

The improvement in overall cognitive EA from 6 to 19 21 months was largely due to progress in conceptual development and reasoning, in which the boy came close to the mean for his age group. At age 40 months, he picked up objects that were presented to him, responded to instructions, and generally showed awareness of his ability to cause and modify external events. His relative development was more stable as regards perceptual development and memory.

In October 1998, at the age of 36 months, the boy began to attend pre-school. So far, his vachers consider his attitude very positive. He participates keenly in all group activities and is very interested in all the activities in which he can take part. Because of his lack of mobility, his companions do not interact with him very much, but there do not appear to be any serious social problems when interaction does occur.

\section{Discussion}

In conclusion, the child has made slow but significant progress since the start of therapy, not only in specific developmental areas but also in his general attitude to and capacity for learning. He currently accepts changes in activity willingly, is able to work in a large group, understands instructions, and is able to express himself by means of gestures. Our main task is now to achieve greater parental involvement in his therapy so as maximize his autonomy and his integration in his home environment.

Notwithstanding the foregoing, it is clear that the child's progress is insufficient to prevent him falling incrcasingly behind the normal level for his age group. He seems to belong to Steinlin's severely affected (Class 2 ) category (Steinlin et al., 1997), with less than $63 \%$ of normal development. We are continuing to provide stimulation therapy and to monitor his development so as to detect possible changes in the current developmental trend. Unfortunately, we know of no case studies with which this work can be compared in detail.

\section{References}

Allen, G., Buxton, R., Wong. E., \& Courchesne, E. (1997). Attentional activation of the cerebellum independent of motor involvement. Science, 275, 1940-1943.

Bluma, S., Shearer, M., Frohman, A., \& Hiliiard, J. (1972). Ponage guide to early education. Portage, Wi: Cooperative Educational Service Agency 12. 
Bolthauser, E. (1991). CHARGE and Joubert syndromes are different [Letter]. Pediatrics Nemology, 7, 310.

Brunet, O. \& Lézine. 1. (1965). Le dévelopenent psychologie de la premiére enfance. Paris: Presses Universitaries de Fitance. (Spanish translation: Pereda. S. Escala de Desarrollo Psicomotor de la Primera Infancia O. Bnnlet-1. Lébine. Madrid: Symtec. 1997).

Buceta, M.J., \& Torres, M.C. (1995). Programas de intervención temprana: implicaciones educativas. Revista Galega de Pricopedagoxí, 12, 259-272.

Courchesne, E., Yeung-Courcliesne, R., \& Press, G. (1988). Hypoplasia of cerebellar vermal lobules VI and VII in autism. New England Journal of Medicine, 318, 1349-1354.

Deoma. T., \& Ziegler, A. (1993). Cognitive development and behavior in Joubert syndrome [Letter]. Biological Psychiatry, 33, 854-855.

Fennell, E., Gitten, J., Dede, D., \& Maria, B. (1999). Cogntition, behavior, and development in Jouhert syndrome. Joumal of Child Neurology, 14, 592-596.

Gitten. J., Dede, D., \& Fennell. E. (1998). Neurobehavjoraf development in Joubert syndrome. Joumal of Child Neurology, 13,391-397.

Holroyd, S. Reiss, A., \& Bryan, N., (1991). Autistic fealures in Joubert syndrome: A genetjc disorder with agenesis of the cerebral vermis. Biological Psychiatry, 29, 287-294.

Houdon, S., Onno, K., Takashimas, S., \& Takeshita, K. (1986). Joubert syndrome associated with unisateral ptosis and Leher congenital amaurosis. Pediatrics Neurology, 2, 102-105.

Joubert, M., Eisenring, J., Preston. R., \& Andermam, F. (1969). Familial agenesis of the cerebellar vermis. A syndrome of episodic hyperpnea abnormal eye movements, ataxia, and retardation. Neurology, 19, 813-815.

Leuscher, J.. Dede, D.. Gitten, J., Fennell, E., \& Maria, B. (1999). Parental burden, coping, and family functioning in primary caregivers of children with Joubert syndrome. Joumal of Child Neurology, 14, 642-648.

Maria, B., Bolthauser, E.. Palmer, S., \& Tran. T. (1999). Clinical features and revised diagnostic criteria in Jouber syndrome. Journal of Child Neawology. 14, 583-590.

Maria. B., Hoang, K., \& Tusa, R. (1997). "Joubert syndrome" revisited: Key ocular motor signs with magnetic resonance imaging correlation. Journal of Child Neurology, 12, 423-430.

Newbory, J., Stock, J., Wnek, L., Guidubaldi, J., \& Svinicki, J. (1984). The Battelle Developmental Inentory. Allen. MA:
DIM Teaching Resources. (Spanish translation: De la Cru\% M.. \& Goncález. M. Inwentario de Dexarollo Battelle. Madrid: TEA. 1996).

O'Brien, G., \& Yule, W. (1995). Behanionard phonotyes. London: Mac Keith Press.

Ozonoff, S., Williams. B., Gale. S. \& Miller, J. (1999), Autism and attistic fichavior in Jouhert syndrome. Jommal of Child Neurology, 14, 636-641

Pellegrino, J.. Lenssch, W.. Muenke, M.. de Chance. P. (1997). Clinical and molecular analysis in Joubert symdrome. Amorican Jommal of Medical Genetics, 72, 59-62.

Saar, K., A1-Gazali, L.. Sztriha. L., Rueschendor, F., Nur-E-Kamal, M., Reis, A., \& Bayoumi, R. (1999). Honnorigosity mapping in families with foubert syndrome identities a locus on chromosome $9 \mathrm{q} 34.3$ and evidence for genetic heterogeneity.

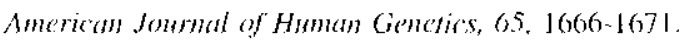

Saraiva, J.M. \& Baraitser, M. (1992). Joubert syndrome: A review. American Jomnal of Modical Geneticx, 4,3,726-731.

Shoumitro, 1). (1998). Sell-injurious behaviour as a past of genetic syndromes. British Jommal of Psychiame: 772, 385-388.

Steinlin, M. (1998). Non-progressive congenital ataxias. Brein de Derelopmont, 20, 199-208.

Steinlin, M. Schnid. M. Landau. K., \& Boltshauser, E. (1997). Follow-up in children with Joubest syndrome. Neturopediatrics, 28. 204-205

Torres, M.C. \& Buceta, M.J. (1996). Estimulación precoz y desarrollo cognoseitivo en un grupo de sujetos con sindrome de Down. Psicología Contemporínea, 3, 72-78

Torres, M.C.. \& Buceta, M.J. (1997). Intervención oportuna en niños con síncrome de Dow'r de 0-2 años: importancia de la participación de los padres. Rovista de Pricologia General y Aplicada, 50. 371-388.

Torres, M.C.. \& Buceta. M.J. (1998). Effect of parental intervention on motor developtment of Dow'r syndtome infants between hirth and age two years. The British Joumal of Developmental Disabilities. 44, 94-101.

Torres, M.C.. Buceta, M.J. \& Lorenzo, J. (2000). The development of a child with Potter's sequence due to unilateral renal agenesis. The British Joumat of Developmental Disabilities, 46, 63-71.

Received September 27, 1999

Revision received October 17,2000 Accopted January 23, 2001 